\title{
A biblioteca escolar na pauta do Congresso Nacional
}

\author{
The school library on the agenda of Congress
}

\author{
Francisco de Paula Araújo \\ Mestre em Políticas Públicas e Formação Humana pela Universidade do Estado do Rio de Janeiro - UERJ. \\ Bibliotecário da Universidade Federal do Rio de Janeiro - UFRJ. \\ Editor chefe da Revista Biblioo: Cultura Informacional. \\ E-mail: chicoval@gmail.com
}

\begin{abstract}
Resumo
Discorre sobre as leis discutidas, votadas ou por votar no contexto atual pelo Legislativo brasileiro acerca do tema da biblioteca escolar, com especial atenção para a Lei n ${ }^{\circ} 12.244$ de 2010 e os Projetos de Lei da Câmara ${ }^{\circ} 28$ de 2012, que visa alterar a Lei $\mathrm{n}^{\circ} 9.394$, de 20 de dezembro de 1996 - LDB, e o de $\mathrm{n}^{\circ} 6.038$ de 2013, que busca regulamentar o exercício da atividade profissional de Técnico em Biblioteconomia. Evidencia os dilemas inerentes à regulamentação quando as condições não são favoráveis para tanto. Valeu-se para essa pesquisa das fontes de pesquisa legislativas oficiais, como os sites do Planalto, da Câmara e do Senado. Conclui-se pela emergência do reconhecimento da biblioteca escolar enquanto espaço indispensável para a democratização do conhecimento, ao mesmo tempo em que os esforços ainda parecem ser desconexos da realidade.
\end{abstract}

Palavras-chave: Biblioteca Escolar. Legislação. Congresso Nacional

\begin{abstract}
Examines the role of Congress in the current discussion and adoption of legal devices that somehow relate to the school library. Lists the laws discussed, voted or vote in the current context by the Brazilian Congress, with special attention to Law No. 12,244, 2010 and the Bills of the House No. 28 of 2012 to amend Law No. 9,394, of December 201996 - LDB, and No. 6038 of 2013, seeks to regulate the exercise of professional activity in the Technical Library. Highlights the dilemmas inherent in regulation when conditions are not favorable for both. Thanks to this survey of research sources legislative officers, as the sites of the Plateau, the House and Senate. It concludes the emergence of recognition of the school library as spaces essential to the democratization of knowledge, at the same time that efforts still seem to be disconnected from reality.
\end{abstract}

Keywords: School Library. Legislation. Congress. 


\title{
Introdução
}

As bibliotecas nascem no Brasil junto com a escola e vice-versa, conforme nos ensina a doutrina biblioteconômica mais consistente (MORAES, 2006). Tendo se instalado por aqui a partir de 1549, ou seja, nove anos após a fundação da Companhia de Jesus, os jesuítas, chefiados por Manuel da Nóbrega, "traziam livros, mas não na quantidade necessária para suprir os colégios que fundaram logo em seguida em diversas partes da colônia”. Lançando mão de um processo de compilação das cartilhas e desenvolvimento das coleções, os jesuítas fizeram organizar as maiores e melhores bibliotecas do Brasil colonial, as quais estavam a serviço, sobretudo de seus estabelecimentos de ensino. Mesmo reconhecendo o pouco conhecimento acerca das outras ordens, Rubens Borba de Moraes (2006, p. 3) admite que as bibliotecas dos jesuítas fossem melhores e mais numerosas, tendo este como base os relatos do próprio padre Antônio Vieira.

\begin{abstract}
A biblioteca do colégio Santo Alexandre do Pará, em 1760, tinha mais de 2000 volumes. A do colégio de Vigia, 1010 volumes [...]. Serafim Leite [padre que escreveu a História da Companhia de Jesus no Brasil] calcula em 12000 os livros existentes no Maranhão e no Pará. O colégio do Rio de Janeiro tinha 5434 volumes em meados do século XVIII. Mas a mais rica de todas estava em Salvador [...]. Essa biblioteca, começada modestamente com as obras trazidas pelo padre Manuel da Nóbrega, em 1549, chegaria a possuir 15000 volumes quando foram expulsos os jesuítas (MORAES, 2006, p. 8).
\end{abstract}

Em nossos tempos, entretanto, a biblioteca, em geral, e a biblioteca escolar, em particular, parece não gozar nem do mesmo prestígio, nem da mesma preocupação, seja por parte de uma sociedade como a nossa, pouco afeita aos livros e à leitura, seja por parte do poder público, cujas ações nesse campo têm sido muito modestas, sobretudo na seara legislativa.

Conforme dispõe de forma expressa a Constituição Federal de 1988, "todo o poder emana do povo, que o exerce por meio de representantes eleitos ou diretamente, nos termos desta Constituição" (art. $1^{\circ}$, parágrafo único, grifo nosso). Nestes termos, o Congresso Nacional realizaria a vontade popular, aprovando e rejeitando projetos de lei que ora atendem os anseios do cidadão, ora contrariam a vontade geral. Em relação às bibliotecas escolares, a necessidade de sua regulamentação parece se impor num país muitas vezes apontado como tradicionalmente avesso aos livros, à leitura, às bibliotecas e a seus profissionais, como bem já destacamos.

Em tempo, a IFLA/UNESCO estabeleceu por meio de seu manifesto para as bibliotecas escolares que "a responsabilidade sobre a biblioteca escolar cabe às autoridades locais, regionais e nacionais, portanto deve essa agência ser apoiada por política e legislação específicas" (IFLA; UNESCO, 2002, grifo nosso). 
O objetivo deste trabalho é analisar o papel do Congresso Nacional na atual discussão e aprovação de dispositivos legais que de alguma forma dizem respeito à biblioteca escolar. Para tanto se elenca as leis discutidas, votadas ou por votar no contexto atual pelo Legislativo brasileiro, com especial atenção para a Lei no 12.244 de 2010, lei de universalização das bibliotecas escolares, e o Projeto de Lei da Câmara $n^{\circ} 28$ de 2012, que visa alterar a Lei $n^{\circ}$ 9.394, de 20 de dezembro de 1996 - LDB - e Projeto de Lei nº 6038 de 2013, que visa regulamentar o exercício da atividade profissional de Técnico em Biblioteconomia.

A pesquisa se valeu de pesquisa legislativa, sobretudo nas fontes oficiais, e doutrinárias, concluindo pela emergência do reconhecimento da biblioteca escolar enquanto instrumento indispensável para a democratização do conhecimento, ao mesmo tempo em que se admite que os esforços ainda pareçam ser desconexos da realidade.

\section{Lei $n^{0}$ 12.244 de 2010, lei de universalização das bibliotecas escolares}

Quando a Lei número 12.244 foi sancionada em 2010, a classe biblioteconômica vibrou, pois, as novas regras pareciam indicar um mundo de possibilidades, sobretudo no campo profissional, como na abertura de novos postos de trabalho, seja para os bibliotecários, seja para os educadores, posto que a biblioteca seja um instrumento fundamental no processo de educação. Mais de quatro anos após a entrada em vigor, a Lei mostra seus primeiros percalços, cujos dilemas só agora, após um esboço de debate, começam a ser identificados.

Conforme consta, as leis são cartas de intenções. Dessa forma, sua promulgação não significa sua realização. Ao contrário, diz-se que a lei tem de "pegar", ou seja, se fazer reconhecer pela sociedade para que sua observância seja possível. Mas como fazer uma lei "pegar" sem condições estruturais mínimas para tanto? Como sensibilizar os gestores públicos e a iniciativa privada para a questão da biblioteca? Como lhes garantir estrutura física e profissionais qualificados para tal empreendimento? Estas e outras perguntas permeiam a discussão acerca da obrigatoriedade da biblioteca escolar, com bibliotecários, nos estabelecimentos de ensino do país, sejam eles públicos ou privados.

De acordo com o Censo Escolar da Educação Básica de 2011 (Pesquisa do feita pelo Inep), existem hoje 194.932 estabelecimentos de ensino de Educação Básica pelo Brasil, sendo 157.381 na rede pública e 37.551 na rede privada. Já os bibliotecários somam 34 mil inscritos 
no sistema $\mathrm{CFB} / \mathrm{CRBs}^{1}{ }^{1}$, sendo que destes apenas 18 mil estão ativos. A disparidade entre os números é gritante.

Os números demonstram de pronto um problema a ser superado que a lei por si só não dá conta: o número infinitamente inferior de profissionais bibliotecários frente ao número de estabelecimentos de ensino.

O prazo para adequação dos estabelecimentos de ensino à Lei foi fixado em dez anos (art. $3^{\circ}$ ) a partir de sua publicação que, como já informado, entrou em vigor no ano de 2010, ficando o prazo final para o ano de 2020. Com isso, seriam necessários que se formassem em torno 24 mil bibliotecários por ano para que se pudesse dar conta da demanda, algo que se mostra impossível tendo em vista o número insuficiente de instituições que formam esses profissionais.

\section{Projeto de Lei da Câmara no 28 de 2012, que visa alterar a Lei de Diretrizes e Base da Educação}

Em meados de setembro de 2013 a Comissão de Educação do Senado aprovou o projeto de lei que torna obrigatória a existência de biblioteca com bibliotecários para o funcionamento de escolas do Ensino Básico, que engloba da Educação Infantil, passando pelo Fundamental, até o Médio. A notícia não só repete como pode agravar o dilema trazido pela Lei das Bibliotecas Escolares. Isso por que esta, caso aprovada, diminui o prazo de adaptação dos estabelecimentos de 10 para cinco anos, a contar da data de sua publicação, tornado impossível o que já era difícil.

Mas apesar do dilema, o PLC (que visa alterar a Lei nº 9.394, de 20 de dezembro de 1996 - LDB), deixa em aberto àquilo que a classe biblioteconômica tanto rechaçava: perder parte de sua reserva de mercado. Isso porque, conforme o texto da proposta, a União, os estados e os municípios estariam autorizados a condicionar o funcionamento dos estabelecimentos do seu sistema de ensino à disponibilidade de bibliotecas escolares, assistidas por bibliotecários com formação em nível superior "ou profissionais da educação com capacitação específica".

\footnotetext{
${ }^{1}$ Números completos estão disponíveis em: <http://blog.crb6.org.br/artigos-materias-e-entrevistas/cfb-divulga-onumero-de-bibliotecarios-no-brasil/>.
}

Bibl. Esc. em R., Ribeirão Preto, v. 4, n. 1, p. 26-36, 2015. 
A expressão "ou profissionais da educação com capacitação específica” parece autorizar que professores, mediante especialização na área de Biblioteconomia, assumam as bibliotecas, o que parece bastante razoável, em vista do que foi apontado anteriormente, ou seja, a discrepância entre o número de profissionais e o número de estabelecimentos educacionais. Entretanto, este parece ser um ponto apto a gerar controvérsias entre os profissionais bibliotecários que certamente argumentarão pela possível perda de sua reserva de mercado conquistada com a Lei $\mathrm{n}^{\circ}$ 12.244/10.

Razoável também pelo fato de que as bibliotecas escolares não poderiam deixar de ser criadas pelo simples fato de que uma determinada categoria profissional, neste caso os bibliotecários, não foi capaz de se organizar para dar conta de uma demanda. A educação não pode ser sacrificada em face do mercado de trabalho. Conforme nos ensina o ministro do Supremo Tribunal Federal (STF), Luiz Roberto Barroso (2009, p. 70-71), o interesse público (que nesta hipótese é o acesso ao conhecimento por meio da biblioteca escolar) tem supremacia sobre o interesse privado (que neste caso é a reserva de mercado da categoria).

Além disso, a ideia de professores assumindo bibliotecas escolares não é de todo desarrazoada, uma vez que essa é uma prática bem aceita em outros países. Em entrevista a edição 6 da Revista Biblioo, o conselheiro de Secretarias de Educação nos estados alemães de Hessen e Berlim-Brandenburgo, GunterSchlamp, explicou que naquele país a escola oferece para um ou dois professores a formação de professor-bibliotecário ou de especialista em mídias:

O curso dos professores-bibliotecários para todas as escolas deve ser o primeiro passo; o distrito ou estado estabelece uma central de serviços com uma equipe de bibliotecário, especialistas em mídias e profissionais de TI. Eles aconselhariam as escolas e ajudariam a preparar os cursos de treinamento.

Nesta mesma edição da Revista, a bibliotecária colombiana Silvia Castrillón disse algo que ela julga impopular entre os bibliotecários: a possibilidade de professores assumirem a biblioteca escolar:

Acredito que as bibliotecas escolares poderiam ser tratadas por professores com conhecimentos de Biblioteconomia. Eu acho que os conhecimentos de Biblioteconomia são necessários, mas que as bibliotecas devem colocar o foco em pedagogia. Mas também acredito que a formação do bibliotecário deveria estar mais voltada para questões relacionadas com a cultura escrita, leitura, escrita, a formação de leitores, livros (não somente de literatura), literatura etc.

Não é a toa que Castrillón se sinta constrangida com a ideia de um professorbibliotecário. No Brasil quase toda a classe biblioteconômica rechaça por completo a ideia. $\mathrm{O}$ Conselho Federal de Biblioteconomia, por exemplo, fez circular na internet uma petição 
pública $^{2}$ na qual solicitava a supressão da expressão "ou profissionais da educação com capacitação específica" que constava da proposta da Lei em análise.

A empreitada parece ter logrado êxito (pelo menos em parte), pois no dia 04 de outubro de 2013 o senador Paulo Paim (PT/RS) apresentou um substitutivo ao anterior. À antiga proposta foi acrescentada a expressão "capacitação específica em biblioteca escolar e sob a supervisão do bibliotecário", fazendo com que a discussão retornasse quase que a estaca zero. Na justificativa desse novo substitutivo, Paim reconheceu como aspecto positivo o fato de se tornar obrigatória a criação e a manutenção de bibliotecas nessas instituições, mas apontou como ponto negativo o fato do texto permitir a contratação de outros profissionais da educação, mas sem capacitação específica em biblioteca escolar.

De acordo com o senador (BRASIL, 2013a),

O caráter negativo da permissão para a contratação desses profissionais deve-se ao alcance das expressões profissionais da educação e capacitação específica, uma vez que o texto não esclarece o significado de ambas, permitindo interpretações que podem contrariar os fins do Substitutivo e as responsabilidades técnicas, políticas e sociais dessas bibliotecas.

Caso aprovada a Lei, as bibliotecas escolares até poderão ser assumidas por outros profissionais da educação, mas com duas condições: 1) Que este profissional tenha "capacitação específica em biblioteca escolar", ou seja, tenha um curso direcionado as atividades que serão desenvolvidas naquele ambiente e 2) Que esse profissional seja supervisionado por um bibliotecário. Com essa nova proposta, o problema da falta de bibliotecários persiste, a não ser que se recorra à interpretação da Lei segundo a qual essa supervisão possa ser feita sem limite de estabelecimentos supervisionados por um único profissional bibliotecário.

Outro problema que pode ser trazido pela nova lei em caso de aprovação é o que diz respeito ao prazo de adequação dos estabelecimentos de ensino. O prazo fixado é de cinco anos a partir de sua publicação, se confrontando com os dez anos estabelecidos pela Lei das bibliotecas escolares discutida acima (dos quais restam pouco mais de seis). Neste caso teríamos

\footnotetext{
${ }^{2}$ Disponível em: http://www.peticaopublica.com.br/?pi=P2013N43943
} 
A biblioteca escolar na pauta do Congresso Nacional

um conflito de leis no tempo, caracterizando-se o que na ciência jurídica se convencionou chamar antinomia real ${ }^{3}$, com algumas possibilidades de resolução ${ }^{4}$.

Vale ressaltar, entretanto, que tal possibilidade só existiria em caso de aprovação desta Lei, uma vez que um dos critérios para que haja antinomia jurídica real é que as normas conflitantes "sejam vigentes e pertencentes a um mesmo ordenamento jurídico" (BOAVENTURA, 2007, p. 8, grifo nosso).

Como esse PLC ainda está em discussão (ver quadro 1), não vale a pena tecer maiores comentários sobre ele, posto que a situação possa mudar a qualquer momento.

Quadro 1- Sintético da situação atual do Projeto de Lei da Câmara no 28 de 2012

\begin{tabular}{|c|c|c|}
\hline Texto original da Lei & $\begin{array}{l}\text { Emenda } \mathrm{n}^{\mathbf{0}} 1 \text { ao PLC } \mathrm{n}^{\mathbf{0}} 28 / 2012 \\
\text { apresentada pelo senador Cássio } \\
\text { Cunha Lima }\end{array}$ & $\begin{array}{l}\text { Emenda } n^{\circ} 2 \text { ao PLC } n^{\circ} 28 / 2012 \\
\text { apresentada pelo senador Paulo } \\
\text { Paim }\end{array}$ \\
\hline $\begin{array}{l}\text { “Art. } 9^{\circ} \text { A União } \\
\text { incumbir-se-á de: } \\
\text { II - organizar, manter e } \\
\text { desenvolver os órgãos e } \\
\text { instituições oficiais do } \\
\text { sistema federal de ensino e } \\
\text { o dos Territórios; }\end{array}$ & $\begin{array}{l}\text { "Art. } 9^{\circ} \text { A União incumbir-se-á de: } \\
\text { II - organizar, manter e desenvolver os } \\
\text { órgãos e instituições oficiais do sistema } \\
\text { federal de ensino e o dos Territórios e } \\
\text { garantir a criação e a manutenção de } \\
\text { bibliotecas escolares nessas instituições, } \\
\text { assistidas por bibliotecários com formação } \\
\text { em nível superior ou profissionais da } \\
\text { educação com capacitação específica; }\end{array}$ & $\begin{array}{l}\text { "Art. } 9^{\circ} \text { A União incumbir-se-á de: } \\
\text { II - organizar, manter e desenvolver os } \\
\text { órgãos e instituições oficiais do sistema } \\
\text { federal de ensino e o dos Territórios e } \\
\text { garantir a criação e a manutenção de } \\
\text { bibliotecas escolares nessas instituições, } \\
\text { assistidas por bibliotecários com } \\
\text { formação em nível superior ou } \\
\text { profissionais da educação com } \\
\text { capacitação específica em biblioteca } \\
\text { escolar e sob a supervisão do } \\
\text { bibliotecário; }\end{array}$ \\
\hline $\begin{array}{l}\text { "Art. } 10 \ldots \\
\text { I - organizar, manter e } \\
\text { desenvolver os órgãos e } \\
\text { instituições oficiais dos } \\
\text { seus sistemas de ensino; } \\
\text { IV - autorizar, reconhecer, } \\
\text { credenciar, supervisionar e }\end{array}$ & $\begin{array}{l}\text { "Art. } 10 \ldots \\
\text { I - organizar, manter e desenvolver os } \\
\text { órgãos e instituições oficiais dos seus } \\
\text { sistemas de ensino e garantir a criação e } \\
\text { manutenção de bibliotecas escolares nessas } \\
\text { instituições, assistidas por bibliotecários } \\
\text { com formação em nível superior ou }\end{array}$ & $\begin{array}{l}\text { "Art. } 10 \ldots \\
\text { I - organizar, manter e desenvolver os } \\
\text { órgãos e instituições oficiais dos seus } \\
\text { sistemas de ensino e garantir a criação e } \\
\text { manutenção de bibliotecas escolares } \\
\text { nessas instituições, assistidas por } \\
\text { bibliotecários com formação em nível }\end{array}$ \\
\hline
\end{tabular}

\footnotetext{
${ }^{3}$ De acordo com Tércio Sampaio Ferraz Júnior (1978, p.14, apud BOAVENTURA, 2007) antinomia jurídica real é a oposição que ocorre entre duas normas contraditórias (total ou parcialmente), emanadas de autoridades competentes num mesmo âmbito normativo que colocam o sujeito numa posição insustentável pela ausência ou inconsistência de critérios aptos a permitir-lhe uma saída nos quadros de um ordenamento dado.

${ }^{4}$ Conforme destaca Boaventura (2007, p. 11), "os critérios ou de regras fundamentais para solução de antinomia são de três tipos: o cronológico, o hierárquico e o da especialidade". Pelo critério da especialidade, por exemplo, a Lei das Bibliotecas Escolares prevaleceria sobre a nova Lei por tratar especificamente de algumas das questões que visa regulamentar, neste caso o prazo para que os estabelecimentos de ensino se adéquem as exigências legais.
} 


\begin{tabular}{|c|c|c|}
\hline $\begin{array}{l}\text { avaliar, respectivamente, } \\
\text { os cursos das instituições } \\
\text { de educação superior e os } \\
\text { estabelecimentos do } \\
\text { seusistema de ensino; }\end{array}$ & $\begin{array}{l}\text { profissionais da educação com capacitação } \\
\text { específica; } \\
\text { IV - autorizar, reconhecer, credenciar, } \\
\text { supervisionar e avaliar, respectivamente, os } \\
\text { cursos das instituições de educação superior } \\
\text { e os estabelecimentos dos seus sistemas de } \\
\text { ensino, condicionando o funcionamento das } \\
\text { escolas de educação básica à } \\
\underline{\text { disponibilidade de bibliotecas escolares, }} \\
\underline{\text { assistidas por bibliotecários com formação }} \\
\underline{\text { em nível superior ou profissionais da }} \\
\underline{\text { educação com capacitação específica; }}\end{array}$ & $\begin{array}{l}\text { superior ou profissionais da educação } \\
\text { com capacitação específica em } \\
\text { biblioteca escolar e sob a supervisão do } \\
\text { bibliotecário; } \\
\text { IV - autorizar, reconhecer, credenciar, } \\
\text { supervisionar avaliar, } \\
\text { respectivamente, os cursos das } \\
\text { instituições de educação superior e os } \\
\text { estabelecimentos dos seus sistemas de } \\
\text { ensino, condicionando o funcionamento } \\
\text { das escolas de educação básica à } \\
\text { disponibilidade de bibliotecas escolares, } \\
\text { assistidas por bibliotecários com } \\
\text { formação em nível superior ou } \\
\text { profissionais da educação com } \\
\text { capacitação específica em biblioteca } \\
\text { escolar e sob a supervisão do } \\
\text { bibliotecário; }\end{array}$ \\
\hline $\begin{array}{l}\text { "Art. 11... } \\
\text { I - organizar, manter e } \\
\text { desenvolver os órgãos e } \\
\text { instituições oficiais dos } \\
\text { seus sistemas de ensino, } \\
\text { integrando-os às políticas } \\
\text { e planos educacionais da } \\
\text { União e dos Estados; } \\
\text { IV - autorizar, credenciar e } \\
\text { supervisionar } \\
\text { estabelecimentos do seu } \\
\text { sistema de ensino; }\end{array}$ & $\begin{array}{l}\text { "Art. 11... } \\
\text { I - organizar, manter e desenvolver as } \\
\text { instituições oficiais e os órgãos dos seus } \\
\text { sistemas de ensino, integrando-os às } \\
\text { políticas e planos educacionais da União e } \\
\text { dos Estados e garantindo, nas escolas das } \\
\underline{\text { respectivas redes, a criação e a manutenção }} \\
\underline{\text { de bibliotecas assistidas por bibliotecários }} \\
\underline{\text { com formação em nível superior ou }} \\
\text { profissionais da educação com capacitação } \\
\underline{\text { específica; }} \\
\text { IV - autorizar, credenciar e supervisionar os } \\
\text { estabelecimentos do seu sistema de ensino, } \\
\underline{\text { condicionando o seu funcionamento à }} \\
\underline{\text { disponibilidade de bibliotecas escolares, }} \\
\underline{\text { assistidas por bibliotecários com formação }} \\
\underline{\text { em nível superior ou profissionais da }} \\
\underline{\text { educação com capacitação específica; }}\end{array}$ & $\begin{array}{l}\text { "Art. 11... } \\
\text { I - organizar, manter e desenvolver as } \\
\text { instituições oficiais e os órgãos dos seus } \\
\text { sistemas de ensino, integrando-os às } \\
\text { políticas e planos educacionais da } \\
\text { União e dos Estados e garantindo, nas } \\
\text { escolas das respectivas redes, a criação } \\
\text { e a manutenção de bibliotecas assistidas } \\
\text { por bibliotecários com formação em } \\
\text { nível superior ou profissionais da } \\
\text { educação com capacitação específica } \\
\text { em biblioteca escolar e sob a supervisão } \\
\text { do bibliotecário; } \\
\text { IV - autorizar, credenciar } \\
\text { supervisionar os estabelecimentos do } \\
\text { seu sistema de ensino, condicionando o } \\
\text { seu funcionamento à disponibilidade de } \\
\text { bibliotecas escolares, assistidas por } \\
\text { bibliotecários com formação em nível } \\
\text { superior ou profissionais da educação } \\
\text { com capacitação específica em }\end{array}$ \\
\hline
\end{tabular}




\begin{tabular}{|l|l|l|}
\hline & & $\begin{array}{l}\text { biblioteca escolar e sob a supervisão do } \\
\text { bibliotecário; }\end{array}$ \\
\hline
\end{tabular}

\section{Projeto de Lei $\mathrm{n}^{\circ} 6038$ de 2013, que visa regulamentar o exercício da atividade profissional de Técnico em Biblioteconomia.}

Conforme notícia divulgada no início de agosto de 2013 no site do Partido Socialista Brasileiro (PSB), o deputado federal José Stédile (PSB-RS), presidente da Frente Parlamentar em Defesa da Biblioteca Pública, protocolou no dia 07/08/2013 o Projeto de Lei 6038/2013, que regulamenta o exercício da atividade profissional de Técnico em Biblioteconomia. A iniciativa visaria a atender a solicitação de cursos técnicos dessa área.

De acordo com o projeto (BRASIL, 2013b), as atuais condições impostas pelo crescimento do mercado de trabalho já revelam situações adversas que exigem a intervenção legislativa. Diversas publicações, a exemplo do Censo Escolar 2010 e do site do Conselho Federal de Biblioteconomia, demonstram que, apenas para cumprir a exigência da Lei n. ${ }^{\circ}$ 12.244/10 quanto à formação universitária em Biblioteconomia, seria necessário formar mais de 150 mil bibliotecários nos próximos 10 anos.

Conforme afirma o deputado no PL (BRASIL, 2013b, grifo nosso),

Assim, na falta de profissionais graduados em número suficiente para assumir a função, vem crescendo a procura por profissionais de nível médio para atender as bibliotecas ou os centros de documentação e informação, públicos ou privados, na rede escolar ou universitária, no âmbito comunitário, nas indústrias, nos comércios, nos clubes sociais, nos hospitais, nas instituições culturais etc. A oportunidade e relevância da medida, portanto, são incontestáveis.

De acordo com a Lei $n^{\circ} 9.674 / 1998$, que dispõe sobre o exercício da profissão de Bibliotecário, as Bibliotecas Públicas localizadas em Municípios com até dez mil habitantes e cujo acervo não ultrapasse a duzentos exemplares catalogados poderão funcionar sob a supervisão de um Técnico em Biblioteconomia, devidamente registrado perante o Conselho e, neste caso, deverão comunicar ao respectivo Conselho Regional de Biblioteconomia a criação, o funcionamento e a responsabilidade técnica da Biblioteca, para fins de anotação e controle, sendo isentas de qualquer taxa ou contribuição (artigo $33, \S 3^{\circ}$ ).

Desde o dia 26/09/2013, o PL está na Comissão de Trabalho, de Administração e Serviço Público (CTASP) para o parecer. Encerrado o prazo para apresentação de emendas, nada havia sido apresentado até a data final. 
Como se percebe, o PL ora em análise não tem relação direta com as questões que envolvem a problemática da biblioteca escolar. Contudo, ela se apresenta como uma possibilidade em face da já discutida ausência de profissionais bibliotecários para suprir as necessidades. A exemplo do PL analisado anteriormente, este também está em fase de discussão e é necessário aguardar os desfecho para se saber como vai ficar.

\section{Considerações finais}

O fato de haver tão intensa discussão no Legislativo nacional acerca da biblioteca escolar pode indicar que o tema esteja entrando na pauta das discussões políticas mais sérias. Se assim o for, a biblioteca, em geral, e a biblioteca escolar, em particular, estariam ingressando numa fase de emergência de seus reconhecimentos enquanto espaços indispensáveis para a democratização do conhecimento.

Entretanto, os esforços ainda parecem ser desconexos da realidade, uma vez que se tenta implementar de cima para baixo o que a comunidade, embora necessitada, não se preparou para assumir.

Nossa convicção é a de que a discussão deve se dar num nível mais estrutural, por assim dizer. O que deve ser prezado são antes as condições básicas de educação. Quando as escolas atingirem condições adequadas de funcionamento, a biblioteca escolar se dará se forma automática, pois não se pode pensar uma educação de excelência que prescinda da biblioteca.

Por outro lado, ao acompanhar os debates políticos sobre a questão, fica a séria impressão de que a classe biblioteconômica está muito mais preocupa em imprimir uma exigência legal que só lhes beneficiará. Mas como temos dito, a educação vem antes de tudo, sobretudo do mercado de trabalho. Além disso, como bem atesta Castrillón (2011, p. 39), “A única forma de obter bibliotecas que cumpram esses novos desafios é contar com um bibliotecário que se apresente como um intelectual capaz de assumir um compromisso ético e político com seu país e com a sociedade [...]” e não somente com seus interesses pessoais.

Por isso pensamos que seja necessário mais do que leis para que a biblioteca escolar se torne uma realidade, mesmo reconhecendo a importância destes dispositivos. O que não se pode é esperar que a lei por si só resolva estes problemas, vez que é necessário antes de tudo um 
engajamento profissional visando à melhoria ou a própria existência da biblioteca como espaço de democratização do conhecimento e não somente como um posto de trabalho a ser ocupado.

\section{Referências}

BARROSO, L. R. Curso de Direito constitucional contemporâneo: os conceitos fundamentais e a construção do novo modelo. São Paulo: Saraiva, 2009.

BOAVENTURA, B. J. R. A solução das antinomias jurídicas aparentes inseridas na consolidação das leis. Revista Justiça e História, Porto Alegre, v. 6, n. 2, 2007. Disponível em:

<https://www.tjrs.jus.br/export/poder_judiciario/historia/memorial_do_poder_judiciario/mem omemo_judiciario_gaucho/revista_justica_e_historia/issn_1677065x/v6n12/Microsoft_Word__ARTIGO_A_SOLUxO_DAS_ANTINOMIAS..._Bruno_Boaventura.pdf >. Acesso em: 29 out. 2013.

BRASIL. Senado Federal. Emenda $n^{\circ} 2$ PLEN (Substitutivo ao Substitutivo do PLC n ${ }^{\circ} 28$, de 2012. Diário do Senado Federal, Brasília, 04 out. 2013a. Disponível em:

$<$ http://www.senado.gov.br/atividade/materia/getPDF.asp?t=137721\&tp=1 >. Acesso em: 5 out. 2013.

BRASIL. Congresso Nacional. Projeto de Lei $\mathbf{n}^{\mathbf{0}} 6038$ de 2013: regulamenta o exercício da atividade profissional de Técnico em Biblioteconomia. 07 ago. 2013b. Disponível em: <http://www2.camara.leg.br/proposicoesWeb/prop_mostrarintegra;jsessionid=265643B593A 453F1F3C689416D4349DD.node1 codteor $=1113116 \&$ filename $=P L+6038 / 2013$ > . Acesso em: 5 out. 2013.

BRASIL. Constituição (1988). Constituição da República Federativa do Brasil. Brasília: Senado Federal: Centro Gráfico, 1988.

CASTRILlÓN, S. O direito de ler e escrever. São Paulo: Pulo do Gato, 2011.

As bibliotecas escolares na América Latina estão começando a ter um lugar nas políticas públicas e nas agendas das autoridades da educação, pelo menos em alguns países. [10 de novembro, 2011]. Entrevistador: Chico de Paula. Revista Biblioo, Rio de Janeiro, 10 nov. 2011. Disponível em: < http://biblioo.info/silvia-castillon/>. Acesso em: 26 out. 2013.

IFLA; UNESCO. Manifesto IFLA/UNESCO para bibliotecas escolares. 2002. Disponível em: 〈http://archive.ifla.org/VII/s11/pubs/portuguese-brazil.pdf>. Acesso em: 26 out. 2013.

MORAES, R. B. Livros e bibliotecas no Brasil colonial. 2. ed. Brasília: Briquet de Lemos, 2006.

SCHLAMP, G. Gunter Schlamp: "chegará o dia em que professores europeus irão para o Brasil para aprender como criar boas bibliotecas escolares". [07 de novembro, 2011]. Entrevistadores: Chico de Paula e Emilia Sandrinelli. Revista Biblioo, Rio de Janeiro, 07 nov. 2011. Disponível em: 〈 http://biblioo.info/gunter-schlamp-2/>. Acesso em: 26 out. 2013. 